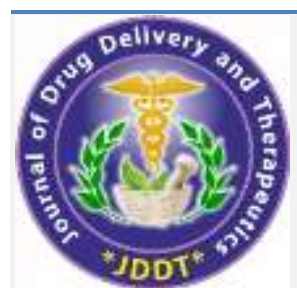

Available online on 15.01.2022 at http://jddtonline.info

\section{Journal of Drug Delivery and Therapeutics}

Open Access to Pharmaceutical and Medical Research

Copyright (C) 2022 The Author(s): This is an open-access article distributed under the terms of the CC BY-NC 4.0 which permits unrestricted use, distribution, and reproduction in any medium for non-commercial use provided the original author and source are credited

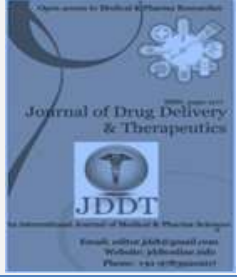

Research Article

\title{
In-silico Absorption, Distribution, Metabolism, Elimination and Toxicity profile of Isopulegol from Rosmarinus officinalis
}

\author{
R.V. Kalaimathi ${ }^{1}$, A. Jeevalatha ${ }^{2}$, A.N. Basha ${ }^{1}$, C. Kandeepan ${ }^{1}$, S. Ramya ${ }^{3}$, T. Loganathan ${ }^{4}$, R. Jayakumararaj ${ }^{3}$ \\ ${ }^{1}$ PG \& Research Department of Zoology, Arulmigu Palaniandavar College of Arts \& Culture, Palani - 624601, TamilNadu, India \\ ${ }^{2}$ Department of Zoology, GTN College, Dindigul, TamilNadu, India \\ ${ }^{3}$ Department of Botany, Government Arts College, Melur - 625106, Madurai, TamilNadu, India \\ ${ }^{4}$ Department of Plant Biology and Plant Biotechnology, LN Government College (Autonomous), Ponneri - 601204, TN, India
}

Article Info:

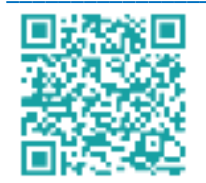

Article History:

Received 17 December 2021 Reviewed 30 December 2021

Accepted 09 January 2022 Published 15 January 2022

\section{Cite this article as:}

Kalaimathi RV, Jeevalatha A, Basha AN, Kandeepan C Ramya S, Loganathan T, Jayakumararaj R, In-silico Absorption, Distribution, Metabolism, Elimination and Toxicity profile of Isopulegol from Rosmarinus officinalis, Journal of Drug Delivery and Therapeutics. 2022; 12(1):102-108

DOI: http://dx.doi.org/10.22270/jddt.v12i1.5188

*Address for Correspondence:

R. Jayakumararaj, Department of Botany, Government Arts College, Melur - 625106, Madurai, TamilNadu, India

\section{Abstract}

Plant Based Natural Products (PBNPs) have contributed to the development of many drugs for diverse indications. Worldwide interest in use of plants based natural products (PBNPs) has been growing, and its beneficial effects being rediscovered for the development of new drugs. Literature survey on indigenous traditional knowledge bestows ethnopharmacological potentials of PBNPs, which has inspired research in drug discovery; further it provides a baseline for the development of novel drug leads against selected pharmacological targets. Studies report that rosemary essential oil (ROEO) extracts have hepatoprotective, antifungal, insecticide, antioxidant and antibacterial properties. However, their application is limited because of their odor, color and taste. Owing to the widespread applications of phytocompounds in ROEO - GCMS was performed. GCMS analysis detected 22 compounds of which 6 compounds were in abundant. In the present study, isopulegol - a Prenol Lipid (Monoterpenoid) from Rosmarinus officinalis has been ADMET characterized from biomedical application point of view.

Keywords: Rosmarinus officinalis; Rosemary officinalis Essential Oils (ROEO); Pharmacological Activity; ADMET; GCMS;

\section{INTRODUCTION}

Rosmarinus officinalis L. (Rosemary) is a medicinal plant native to the Mediterranean region and cultivated around the world 1 . Besides, therapeutic application, it is commonly used as a condiment and preservative. $R$. officinalis is contains many bioactive molecules, phyto-compounds, endowed with pharmacological activities, such as anti-aging, anti-inflammatory, antioxidant, antimicrobial, antiproliferative, antitumor, tumor-protective, tumor-inhibitory and attenuating activities ${ }^{2}$.

Essential oils (EOs) a major group of phytogenic bioactive compounds (PBAC) have been used for variety of purposes over thousands of years. Due to their strong aromatic properties and bioactive nature, EOs has been used in aromatherapy, as flavor and fragrances in cosmetics, foods, and more recently as pharmaceuticals, natural preservatives, additives, and biopesticides ${ }^{3}$. EOs are concentrated form of liquid mixtures of volatile compounds of plant origin with unique structural chemistry including terpenoid and non-terpenoid hydrocarbons and their oxygenated derivatives, with natural color, odor and flavor, or "essence" of their source - volatile/ odoriferous oil. Essential oils are isolated from various plant components such as leaves, fruit, bark, root, wood, heartwood, gum, balsam, berries, seeds, flowers, twigs, and buds 4 .

Role of PBNPs in drug development has been practiced and well documented since antiquity and recently increasing, not because the bioactive compounds are directly used as therapeutic agents but due to fact that they are used as raw material for drug synthesis, or as a base model for new biologically active compounds due to its GRAS nature ${ }^{5-13}$. As people are more concerned about the negative effect of synthetic chemicals in food, there is a need to find "GO" 
products with no or lesser side effects. Therefore, there is a growing interest in using natural extracts as alternatives for synthetic additives because of (a) their synergy with other preservation methods (b) generally regarded as safe, and (c) PBNPs have properties such as antioxidant, antidiabetic, antimutagenic, antitoxigenic and antibacterial. Among the most effective antioxidant constituents of ROEO, cyclic diterpene diphenols, carnosolic acid and carnosol have been identified. In addition, ROEO extract contains carnosic acid epirosmanol, rosmanol, methylcarnosate and isorosmanol. However, validating and using plants as phytopharmaceutical chemistry requires a great deal of basic and applied research, in order to set this resource at the same level of importance of conventional pharmaceutical products $^{14}$

\section{Rosmarinus officinalis L. (Rosemary)}

Rosmarinus officinalis L., commonly known as Rosemary, belongs to the family Lamiaceae. Plants $-2 \mathrm{~m}$ tall. Bark dark grey, irregularly fissured, exfoliating, young branches densely white stellate-tomentulose. Leaves tufted on branches, sessile to short petiolate; leaf blade 1-2.5 $\mathrm{cm} \times 1-2$ $\mathrm{mm}$, leathery, adaxially somewhat shiny, sub-glabrous, abaxially densely white stellate-tomentose, base attenuate, margin entire, revolute, apex obtuse. Calyx ca. $4 \mathrm{~mm}$, densely white stellate tomentose and glandular outside, upper lip sub-circular, teeth of lower lip ovate-triangular. Corolla bluepurple, less than $1 \mathrm{~cm}$, sparsely pubescent outside, tube slightly exserted, apex of upper lip 2-lobed, lobes ovate, middle lobe of lower lip constricted at base into claw, lateral lobes oblong; Fl. Nov ${ }^{15,16}$.

$R$. officinalis has been traced for its origin from the Mediterranean region. It is an aromatic plant, a unique spice commercially available for use as an antioxidant. ROEO extracts have been used for its hepatoprotective potential ${ }^{17}$, therapeutic potential for Alzheimer's disease ${ }^{18}$, and its antiangiogenic effect ${ }^{19}$. On the other hand, it is used in food preservation, because they prevent oxidation and microbial contamination ${ }^{20}$. Therefore, rosemary extract could be useful for replacing or even decreasing synthetic antioxidants in foods. EFSA (European Food Safety Authority) recently, reviewed the safety of rosemary extracts and concluded that there are high-intake estimates ranging from 0.09 (elderly) to 0.81 (children) $\mathrm{mg} / \mathrm{kg}$ per day.

Foliage is used as a common household culinary spice for flavouring. Main constituents of ROEO are camphor (5.0$21 \%), 1,8$-cineole $(15-55 \%), \alpha$-pinene $(9.0-26 \%)$, borneol (1.5-5.0\%), camphene $(2.5-12 \%), \beta$-pinene $(2.0-9.0 \%)$ and limonene $(1.5-5.0 \%)$ in proportions that vary according to the vegetative stage and bioclimatic conditions ${ }^{21}$. ROEO composed of phenolic compounds, di and triterpenes and essential oils. In traditional medicine ROEO is used to treat minor wounds, rashes, headache, dyspepsia, circulation problems, and as an expectorant, diuretic and antispasmodic in renal colic. In addition to their antioxidant properties, ROEO play a very important role in plant defences against herbivores, pathogens and predators; therefore, used to control infectious agents in humans ${ }^{22}$.

A Prenol Lipid (Monoterpenoid) isopulegol (ISO) is an alcoholic monoterpene and has been reported to have a number of pharmacological properties. ISO is endowed with several pharmacological properties being reported in literature such as antihyperlipidemic activity, anxiolytic property, gastro-protective, analgesic, anticancer, antidiabetic and an anticonvulsant activity and even as a flavouring agent. Like other terpenes, ISO is a highly volatile compound that is slightly soluble in water, so its inclusion into cyclodextrins (CDs) is an interesting approach to increase its solubility and bioavailability. In the present study, isopulegol - a Prenol Lipid (Monoterpenoid) from Rosmarinus officinalis has been Absorption, Distribution, Metabolism, Elimination and Toxicity characterized from biomedical application point of view.

\section{MATERIALS AND METHODS}

Collection of Plant material: Rosmarinus officinalis L. (Rosemary) were collected from Palani Hills, Western Ghats ( $2000 \mathrm{~m}$ above the mean sea level), and identity of the plant was confirmed by Botanical Survey of India, Southern circle, Coimbatore, Tamil Nadu. The collected leaves samples were rinsed with tap water dried and powdered and then stored at $4{ }^{\circ} \mathrm{C}$. Plant extracts preparation $5 \mathrm{~g}$ of each sample of $\mathrm{R}$. officinalis was extracted with $100 \mathrm{ml}$ of methanol using Soxhlet apparatus. The extract was filtered and methanol was evaporated by rotary evaporator and then stored at $4^{\circ} \mathrm{C}$ for future use. The methanolic extracts were subjected to chemical tests for the detection of different phytoconstituents using standard procedures.

\section{Preparation and extraction of sample}

Protocol for preparation of sample was according to the methods previously described by Eleyinmi (2007), but with modifications wrt temperature and duration of drying the sample. Sample was prepared according to the methods previously described by Rašković et al., (2015). $25 \mathrm{~g}$ of sample was suspended in $250 \mathrm{~mL}$ of distilled water in stoppered flasks and allowed to stand for $24 \mathrm{~h}$, filtered with Whatman No 24 filter paper, concentrated in a rotary evaporator for $12 \mathrm{~h}$ at $50^{\circ} \mathrm{C}$ and dried in vacuum desiccator. Yield was calculated to be $6.06 \% \mathrm{w} / \mathrm{w}$. Extract was suspended in ethyl acetate and subjected to GC-MS analysis.

\section{GC-MS Analysis}

Phyto-components were identified using GC-MS detection system as previously described Rašković et al., (2015) but with minor modification, whereby portion of the extract was analysed directly by headspace sampling. GC-MS analysis was accomplished using an Agilent 7890A GC system set up with 5975C VL MSD (Agilent Technologies, CA, and USA). Capillary column used was DB-5MS $(30 \mathrm{~m} \times 0.25 \mathrm{~mm}$, film thickness of $0.25 \mu \mathrm{m}$; J\&W Scientific, CA, USA). Temperature program was set as follows: initial temperature $50^{\circ} \mathrm{C}$ held for $1 \mathrm{~min}, 5^{\circ} \mathrm{C}$ per min to $100^{\circ} \mathrm{C}, 9^{\circ} \mathrm{C}$ per min to $200^{\circ} \mathrm{C}$ held for $7.89 \mathrm{~min}$, and the total run time was $30 \mathrm{~min}$. The flow rate of helium as a carrier gas was $0.811851 \mathrm{~mL} / \mathrm{min}$. MS system was performed in electron ionization (EI) mode with Selected Ion Monitoring (SIM). The ion source temperature and quadruple temperature were set at $230^{\circ} \mathrm{C}$ and $150^{\circ} \mathrm{C}$, respectively. Identification of phyto-components was performed by comparison of their retention times and mass with those of authentic standards spectra using computer searches in NIST 08.L and Wiley 7n.l libraries.

\section{ADMET Prediction}

Selected phytocompounds were subjected to ADMET prediction using QikProp (version 4.3, Suite 2015-1; Schrödinger, LLC: New York, NY) and toxicity prediction using TOPKAT (Accelrys, Inc., USA). QikProp develops and employs QSAR/QSPR models using partial least squares, principal component analysis and multiple linear regression to predict physic-chemically significant descriptors (Zhou et al., 2020). 


\section{RESULTS AND DISCUSSION}

\section{Chemical properties and identifier}

Chemical Organic compounds

kingdom

Superclass Lipids and lipid-like molecules

Class

Prenol lipids

Subclass

Monoterpenoids

PubChem 170833

Identifier

Synonyms

ISOPULEGOL;ALPHA-TERPINEOL;

Canonical

SMILES

InChI Key

ZYTMANIQRDEHIO-KXUCPTDWSA-N

\section{GCMS analysis of Rosmarinus officinalis (Rosemary) essential oil}

The chemical composition of EOs depends on plant genetics, growth conditions, development stage at harvest, and processes of extracting active compounds. Different parts of the plant (bark, leaf, fruit and seed) have been extensively investigated for their bioactive phytochemical constituents in various plants (Ramya et al., 2012). GC-MS analysis revealed that the extract of Rosmarinus officinalis contained different volatile oils $\alpha$-Pinene - $\left(\mathrm{C}_{10} \mathrm{H}_{16} \mathrm{O}\right)$, RT - $6.94 \mathrm{~min}, \mathrm{PA}$ - $13.64 \%$; Camphene - $\left(\mathrm{C}_{10} \mathrm{H}_{16}\right)$, RT - $7.38 \mathrm{~min}, \mathrm{PA}-2.42 \%$; $\beta$-Myrcene - $\left(\mathrm{C}_{10} \mathrm{H}_{16}\right)$, RT - $8.88 \mathrm{~min}, \mathrm{PA}-1.19 \%$; $\alpha$-Terpinine - $\left(\mathrm{C}_{10} \mathrm{H}_{16}\right), \mathrm{RT}$ - $9.70 \mathrm{~min}, \mathrm{PA}-0.41 \%$; p-Cymene - $\left(\mathrm{C}_{10} \mathrm{H}_{14}\right)$, RT - 9.98 min, PA - $6.23 \%$; trans-3-Caren-2-ol - $\left(\mathrm{C}_{10} \mathrm{H}_{16} \mathrm{O}\right)$, RT - $10.10 \mathrm{~min}, \mathrm{PA}-0.20 \%$; 1,8-Cineole - $\left(\mathrm{C}_{10} \mathrm{H}_{18} \mathrm{O}\right)$, RT 10.38 min, PA - $41.75 \% ; \gamma$-Terpinene - $\left(\mathrm{C}_{10} \mathrm{H}_{16}\right)$, RT - 11.25 min, PA - $0.59 \%$; $\alpha$-Terpinolene - $\left(\mathrm{C}_{10} \mathrm{H}_{16}\right)$, RT - $12.30 \mathrm{~min}$, PA - $0.35 \%$; Linalool - $\left(\mathrm{C}_{10} \mathrm{H}_{18} \mathrm{O}\right)$, RT - $12.78 \mathrm{~min}, \mathrm{PA}-1.19$ \%; Isopulegol - $\left(\mathrm{C}_{10} \mathrm{H}_{16} \mathrm{O}\right), \mathrm{RT}-14.44 \mathrm{~min}, \mathrm{PA}-13.66 \%$; Eucalyptol - $\left(\mathrm{C}_{10} \mathrm{H}_{18} \mathrm{O}\right)$, RT - $15.21 \mathrm{~min}, \mathrm{PA}-6.71 \%$; Terpinen-4-ol - $\left(\mathrm{C}_{10} \mathrm{H}_{18} \mathrm{O}\right)$, RT - $15.56 \mathrm{~min}, \mathrm{PA}-1.24 \%$; 2Naphthalenol - $\left(\mathrm{C}_{10} \mathrm{H}_{18} \mathrm{O}\right)$, RT - $16.14 \mathrm{~min}, \mathrm{PA}-6.35 \%$; (-)Myrtenol - $\left(\mathrm{C}_{10} \mathrm{H}_{16} \mathrm{O}\right), \mathrm{RT}-16.27 \mathrm{~min}, \mathrm{PA}-0.16 \%$; Verbenone - $\left(\mathrm{C}_{10} \mathrm{H}_{14} \mathrm{O}\right)$, RT - $16.67 \mathrm{~min}, \mathrm{PA}-0.42 \%$; Terpine - $\left(\mathrm{C}_{12} \mathrm{H}_{20} \mathrm{O}_{2}\right)$, RT - $19.42 \mathrm{~min}, \mathrm{PA}-2.80 \%$; $\alpha$-Copaene $\left(\mathrm{C}_{15} \mathrm{H}_{24}\right)$, RT - $22.49 \mathrm{~min}, \mathrm{PA}-0.20 \%$; $\beta$-Caryophyllene $\left(\mathrm{C}_{15} \mathrm{H}_{24}\right), \mathrm{RT}-23.92 \mathrm{~min}, \mathrm{PA}-1.40 \% ; \gamma$-Cadinene - $\left(\mathrm{C}_{15} \mathrm{H}_{24}\right)$, RT - $27.16 \mathrm{~min}, \mathrm{PA}$ - $0.34 \%$; Caryophyllene oxide $\left(\mathrm{C}_{15} \mathrm{H}_{24} \mathrm{O}\right), \mathrm{RT}-28.90 \mathrm{~min}, \mathrm{PA}-0.32 \%$ respectively (Table 1; Fig. 1).

Physicochemical Properties - Molecular weight (154.25 g/mol); LogP (2.36); LogD (2.32); LogSw (-2.59); Number of stereocenters (3); Stereochemical complexity (0.300); Fsp3 (0.800); Topological polar surface area (20.23 Å2); Number of hydrogen bond donors (1); Number of hydrogen bond acceptors (1); Number of smallest set of smallest rings (SSSR) (1); Size of the biggest system ring (6); Number of rotatable bonds (1); Number of rigid bonds (7); Number of charged groups (0); Total charge of the compound (0); Number of carbon atoms (10); Number of heteroatoms (1); Number of heavy atoms (11); Ratio between the number of non-carbon atoms and the number of carbon atoms (0.1);

Druggability Properties of Isopulegol - Lipinski's rule of 5 violations was calculated as 0; Veber rule for Isopulegol was predicated as Good; Egan rule for Isopulegol was predicated as Good; Oral PhysChem score (Traffic Lights) was calculated as 0; GSK's 4/400 score for Isopulegol was predicated as Good; Pfizer's 3/75 score for Isopulegol indicated a Warning; Weighted quantitative estimate of drug-likeness (QEDw) score was calculated as 0.576; Solubility was calculated as 11585.15; Solubility Forecast Index for Isopulegol was ascertained as Good.

ADMET Properties - Human Intestinal Absorption (HIA+) had a predicted probability value - 0.989; Blood Brain Barrier (BBB+) had a predicted probability value - 0.887; Caco-2 permeable (Caco2+) had a predicted probability value - 0.819; P-glycoprotein substrate (Substrate) had a predicted probability value - 0.515; P-glycoprotein inhibitor I (Non-inhibitor) had a predicted probability value - 0.692 ; P-glycoprotein inhibitor II (Non-inhibitor) had a predicted probability value -0.972 .

CYP450 2C9 substrate (Non-substrate) had a predicted probability value - 0.846; CYP450 2D6 substrate (Nonsubstrate) had a predicted probability value - 0.853; CYP450 $3 \mathrm{~A} 4$ substrate (Substrate) had a predicted probability value 0.569; CYP450 1A2 inhibitor (Non-inhibitor) had a predicted probability value - 0.808; CYP450 2C9 inhibitor (Noninhibitor) had a predicted probability value - 0.917; CYP450 2D6 inhibitor (Non-inhibitor) had a predicted probability value - 0.926; CYP450 2C19 inhibitor (Non-inhibitor) had a predicted probability value - 0.856; CYP450 3A4 inhibitor (Non-inhibitor) had a predicted probability value - 0.848 ; CYP450 inhibitory promiscuity (L-CYP Inhibitory Promiscuity) had a predicted probability value -0.883 .

Ames test (Non AMES toxic) had a predicted probability value - 0.956; Carcinogenicity (Non-carcinogens) had a predicted probability value - 0.891; Biodegradation (Ready biodegradable) had a predicted probability value - 0.553 ; Rat acute toxicity $(1.875 \mathrm{LD} 50, \mathrm{~mol} / \mathrm{kg})$ had a predicted probability value - NA; hERG inhibition (predictor I) (Weak inhibitor) had a predicted probability value - 0.655 ; hERG inhibition (predictor II) (Non-inhibitor) had a predicted probability value -0.837 .

Mutagenic property of Isopulegol was none; Tumorigenic property of Isopulegol was none; Irritant property of Isopulegol was none; Effect on reproduction of Isopulegol was none; Drug Likeliness of Isopulegol towards Drugability/ Drug Score was calculated as -21.93; Drugability Score of Isopulegol towards Drugability/ Drug Score was calculated as 0.46 respectively.

Sienkiewicz et al. (2013) reported that rosemary essential oil contains mainly 1,8-cineole (46.4\%), camphor (11.4\%) and $\alpha$-pinene $(11.0 \%)$. The composition of the rosemary essential oil used by Jiang et al. (2011), was composed mainly by 1,8 -cineole $(26.54 \%)$ and $\alpha$-pinene $(20.14 \%)$ Table 2. Biological activities of these secondary metabolites of $R$. officinalis have been reported for its antitumor, antioxidant, anti-infectious, anti-inflammatory, and analgesic activities and effects on the central nervous system, endocrine system, disorders such ascardiac remodeling after myocardial infarction, body weight changes, dyslipidemia, cerebral ischemia, hepato-nephrotoxicity, stress, and anxiety. Anti-inflammatory activity of rosemary has been attributed to the presence and synergistic activity of carnosol and carnosic, rosmarinic, ursolic, oleanolic, and micromeric acids ${ }^{20}$. Specifically, anti-inflammatory activity has been attributed to synergic effects of ursolic and micromeric acids present in ROEO. These natural drugs can be proposed for preclinical and clinical studies in different diseases and pathological conditions. 


\section{CONCLUSION}

Rosemary contains a large variety of bioactive molecules with great therapeutic potential such as triterpenes (e.g., ursolic and oleanolic acid), tricyclic diterpenes (e.g., carnosic acid and carnosol), phenolic acids (e.g., caffeic acid and rosmarinic acid), and essential oils. These secondary metabolites have been formulated in topical dosages. ROEO has anti-inflammatory, antimicrobial, and antioxidant properties, which have been extensively reported in oral formulations. However, development of new formulations containing other less common ROEO extracts is warranted through trials to evaluate and establish the potentials of pharmacologically active phyto-compounds towards safety and efficacy, in treating various pathological conditions.

\section{REFERENCES}

1. De Oliveira JR, Camargo SE, De Oliveira LD. Rosmarinus officinalis L.(rosemary) as therapeutic and prophylactic agent. Journal of Biomedical Science. 2019; 26(1):5-23. https://doi.org/10.1186/s12929-019-0499-8

2. Stevanović ZD, Bošnjak-Neumüller J, Pajić-Lijaković I, Raj J, Vasiljević M. Essential Oils as Feed Additives-Future Perspectives. Molecules. 2018; 23(7):1717. https://doi.org/10.3390/molecules23071717

3. Al-Shalah LA, Hindi NK, Mohsen IH. Essential Oils. Essential OilsBioactive Compounds, New Perspectives and Applications. 2020.

4. Chávez-González ML, Rodríguez-Herrera R, Aguilar CN. Essential oils: A natural alternative to combat antibiotics resistance. Elsevier Academic Press: London Wall, London, UK. 2016:22737. https://doi.org/10.1016/B978-0-12-803642-6.00011-3

5. Ayyappan P, Ganesan K, Jayakumararaj R Ethnobotanic information on uncommon anti-diabetic medicinal plants from Alagarkoil Forest Reserve: Evidence based strategic rationale in management of diabetics. Int J Pharm Res 2019; 16:515-26

6. Ramya, S., Neethirajan, K., \& Jayakumararaj, R. Profile of bioactive compounds in Syzygium cumini-a review. Journal of Pharmacy Research, 2012; 5(8):4548-4553.

7. Sivaperumal R, Ramya S, Ravi AV, Rajasekaran C, Jayakumararaj R. Ethnopharmacological studies on the medicinal plants used by tribal inhabitants of Kottur Hills, Dharmapuri, Tamilnadu, India. Environ We Int J Sci Technol. 2010; 5:57-64

8. Loganathan T, Barathinivas A, Soorya C, Balamurugan S, Nagajothi TG, Jayakumararaj R. GCMS Profile of Bioactive Secondary Metabolites with Therapeutic Potential in the Ethanolic Leaf Extracts of Azadirachta indica?: A Sacred Traditional Medicinal Plant of INDIA. Journal of Drug Delivery and Therapeutics. 2021; 11(4-S):119-26. https://doi.org/10.22270/jddt.v11i4-S.4967

9. Soorya C, Balamurugan S, Basha AN, Kandeepan C, Ramya S, Jayakumararaj R. Profile of Bioactive Phyto-compounds in Essential Oil of Cymbopogon martinii from Palani Hills, Western Ghats, INDIA. Journal of Drug Delivery and Therapeutics. 2021; 11(4):60-5. https://doi.org/10.22270/jddt.v11i4.4887

10. Soorya C, Balamurugan S, Ramya S, Neethirajan K, Kandeepan C, Jayakumararaj R. Physicochemical, ADMET and Druggable properties of Myricetin: A Key Flavonoid in Syzygium cumini that regulates metabolic inflammations. Journal of Drug Delivery and Therapeutics. 2021 Jul 15; 11(4):66-73 https://doi.org/10.22270/jddt.v11i4.4890

11. Sabitha, M., Krishnaveni, K., Murugan, M., Basha, A.N., Pallan, G.A., Kandeepan, C., Ramya, S. and Jayakumararaj, R., In-silico ADMET predicated Pharmacoinformatics of Quercetin-3Galactoside, polyphenolic compound from Azadirachta indica, a sacred tree from Hill Temple in Alagarkovil Reserve Forest, Eastern Ghats, INDIA. Journal of Drug Delivery and Therapeutics, 2021; 11(5-S):77-84 https://doi.org/10.22270/jddt.v11i5-S.5026
12. Loganathan T, Barathinivas A, Soorya C, Balamurugan S, Nagajothi TG, Ramya S, Jayakumararaj R. Physicochemical, Druggable, ADMET Pharmacoinformatics and Therapeutic Potentials of Azadirachtin-a Prenol Lipid (Triterpenoid) from Seed Oil Extracts of Azadirachta indica A. Juss. Journal of Drug Delivery and Therapeutics. 2021;1 1(5):33-46. https://doi.org/10.22270/jddt.v11i5.4981

13. Kandeepan C, Kalaimathi RV, Jeevalatha A, Basha AN, Ramya S, Jayakumararaj R. In-silico ADMET Pharmacoinformatics of Geraniol (3, 7-dimethylocta-trans-2, 6-dien-1-ol)-acyclic monoterpene alcohol drug from Leaf Essential Oil of Cymbopogon martinii from Sirumalai Hills (Eastern Ghats), INDIA. Journal of Drug Delivery and Therapeutics. 2021; 11(4S):109-18. https://doi.org/10.22270/jddt.v11i4-S.4965

14. Atanasov AG, Waltenberger B, Pferschy-Wenzig EM, Linder T, Wawrosch C, Uhrin P, Temml V, Wang L, Schwaiger S, Heiss EH, Rollinger JM, Schuster D, Breuss JM, Bochkov V, Mihovilovic MD, Kopp B, Bauer R, Dirsch VM, Stuppner H. Discovery and resupply of pharmacologically active plant-derived natural products: A review. Biotechnol Adv. 2015; 33(8):1582-1614. https://doi.org/10.1016/j.biotechadv.2015.08.001

15. Gamble, J. S. 1935 "The flora of the Presidency of Madras, London: Adlard\&son." Ltd. London.

16. Matthew, K. M. 1983 "The Flora of Tamil Nadu Carnatic (The Rapinat Herbarium, St. Joseph" s College, Tiruchirapalli, India)." Vol I-III.

17. Rašković A, Milanović I, Pavlović N, Ćebović T, Vukmirović S, Mikov M. Antioxidant activity of rosemary (Rosmarinus officinalis L.) essential oil and its hepatoprotective potential. BMC complementary and alternative medicine. 2014; 14(1):225 https://doi.org/10.1186/1472-6882-14-225

18. Habtemariam $S$. The therapeutic potential of rosemary (Rosmarinus officinalis) diterpenes for Alzheimer's disease. Evidence-Based Complementary and Alternative Medicine. 2016. https://doi.org/10.1155/2016/2680409

19. Kayashima T, Matsubara K. Antiangiogenic effect of carnosic acid and carnosol, neuroprotective compounds in rosemary leaves. Bioscience, biotechnology, and biochemistry. 2012:1111292741 https://doi.org/10.1271/bbb.110584

20. Alavi MS, Fanoudi S, Ghasemzadeh Rahbardar M, Mehri S, Hosseinzadeh $\mathrm{H}$. An updated review of protective effects of rosemary and its active constituents against natural and chemical toxicities. Phytotherapy Research. 2020 0ct 12. https://doi.org/10.1002/ptr.6894

21. Bozin B., Mimica-Dukic N., Samojlik I., Jovin E. Antimicrobial and Antioxidant properties of Rosemary and Sage (Rosmarinus officinalis L. and Salvia officinalis L., Laminaceae) essential oils. J. Agric. Food Chem. 2007; 55:7879-7885 https://doi.org/10.1021/jf0715323

22. Jiang Y., Wu N., Fu Y.-J., Wang W., Luo M., Zhao C.J., Zu Y.G., Liu X.L. Chemical composition and antimicrobial activity of the essential oil of Rosemary. Environ. Toxicol. Pharmacol. 2011; 32:63-68 https://doi.org/10.1016/j.etap.2011.03.011

23. Newman DJ, Cragg GM. Natural products as sources of new drugs over the last 25 years. Journal of natural products. 2007; 70(3):461-77. https://doi.org/10.1021/np068054v

24. Sienkiewicz M., Lysakowska M., Pastuszka M., Bienias W., Kowalczyk E. The potential of use Basil and Rosemary essential oils as effective antibacterial agents. Molecules. 2013; 18:93349351. https://doi.org/10.3390/molecules18089334

25. Tai J., Cheung S., Wu M., Hasman D. Antiproliferation effect of Rosemary (Rosmarinus officinalis) on human ovarian cancer cells in vitro. Phytomedicine. 2012; 19:436-443. https://doi.org/10.1016/j.phymed.2011.12.012

26. Zhou Y, Wu F, Li L, Shen X, Chen G, Wang X, Liang X, Tan M, Huang Z. Computational approaches in preclinical studies on drug discovery and development. Frontiers in Chemistry. 2020; 8:726-31. https://doi.org/10.3389/fchem.2020.00726 


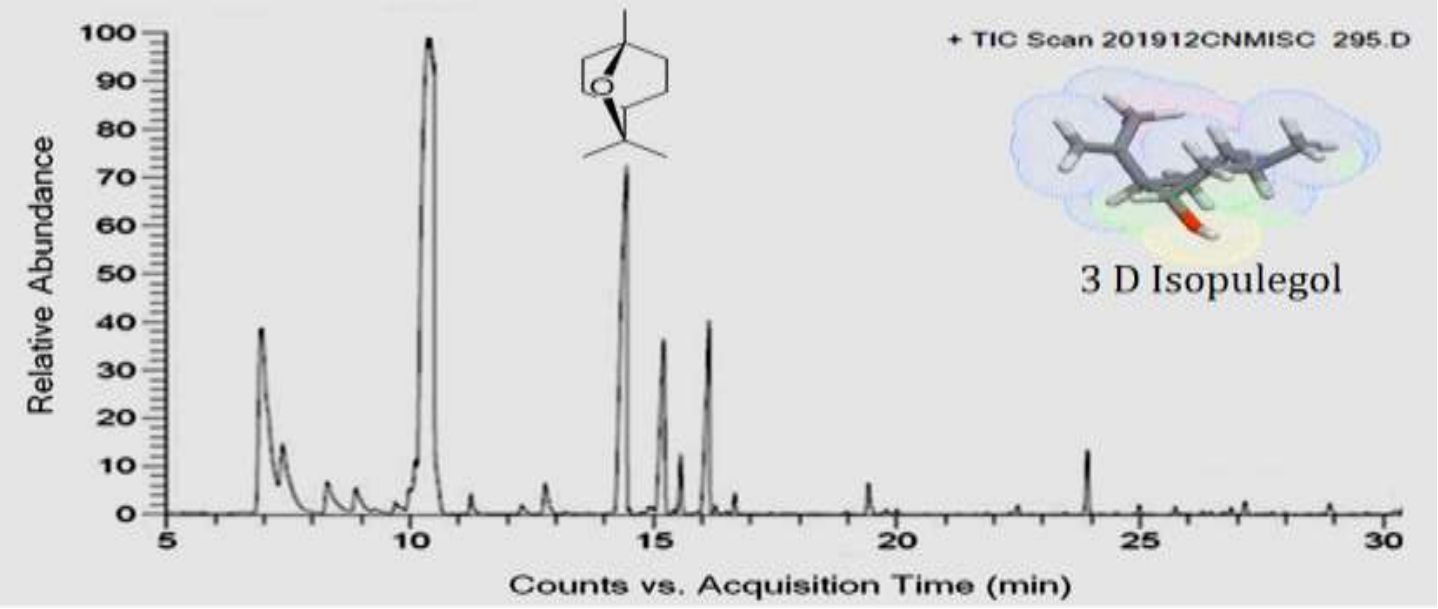

Fig. 1 GCMS analysis of Rosmarinus officinalis (Rosemary) essential oil

Table 1 GCMS profile of Rosmarinus officinalis (Rosemary) essential oil

\begin{tabular}{|c|c|c|c|c|}
\hline S.No & Compound & Molecular Formula & Retention Time (min) & Percentage (\%) \\
\hline 1. & $\alpha$-Pinene & $\mathrm{C}_{10} \mathrm{H}_{16} \mathrm{O}$ & 6.94 & 13.64 \\
\hline 2. & Camphene & $\mathrm{C}_{10} \mathrm{H}_{16}$ & 7.38 & 2.42 \\
\hline 3. & $\beta$-Myrcene & $\mathrm{C}_{10} \mathrm{H}_{16}$ & 8.88 & 1.19 \\
\hline 4. & $\alpha$-Terpinine & $\mathrm{C}_{10} \mathrm{H}_{16}$ & 9.70 & 0.41 \\
\hline 5. & p-Cymene & $\mathrm{C}_{10} \mathrm{H}_{14}$ & 9.98 & 6.23 \\
\hline 6. & trans-3-Caren-2-ol & $\mathrm{C}_{10} \mathrm{H}_{16} \mathrm{O}$ & 10.10 & 0.20 \\
\hline 7. & 1,8-Cineole & $\mathrm{C}_{10} \mathrm{H}_{18} \mathrm{O}$ & 10.38 & 41.75 \\
\hline 8. & $\gamma$-Terpinene & $\mathrm{C}_{10} \mathrm{H}_{16}$ & 11.25 & 0.59 \\
\hline 9. & $\alpha$-Terpinolene & $\mathrm{C}_{10} \mathrm{H}_{16}$ & 12.30 & 0.35 \\
\hline 10. & Linalool & $\mathrm{C}_{10} \mathrm{H}_{18} \mathrm{O}$ & 12.78 & 1.19 \\
\hline 11. & Isopulegol & $\mathrm{C}_{10} \mathrm{H}_{16} \mathrm{O}$ & 14.44 & 13.66 \\
\hline 12. & Eucalyptol & $\mathrm{C}_{10} \mathrm{H}_{18} \mathrm{O}$ & 15.21 & 6.71 \\
\hline 13. & Terpinen-4-ol & $\mathrm{C}_{10} \mathrm{H}_{18} \mathrm{O}$ & 15.56 & 1.24 \\
\hline 14. & 2-Naphthalenol & $\mathrm{C}_{10} \mathrm{H}_{18} \mathrm{O}$ & 16.14 & 6.35 \\
\hline 15. & (-)-Myrtenol & $\mathrm{C}_{10} \mathrm{H}_{16} \mathrm{O}$ & 16.27 & 0.16 \\
\hline 16. & Verbenone & $\mathrm{C}_{10} \mathrm{H}_{14} \mathrm{O}$ & 16.67 & 0.42 \\
\hline 17. & Terpine & $\mathrm{C}_{12} \mathrm{H}_{20} \mathrm{O}_{2}$ & 19.42 & 2.80 \\
\hline 18. & $\alpha$-Copaene & $\mathrm{C}_{15} \mathrm{H}_{24}$ & 22.49 & 0.20 \\
\hline 19. & $\beta$-Caryophyllene & $\mathrm{C}_{15} \mathrm{H}_{24}$ & 23.92 & 1.40 \\
\hline 20. & $\gamma$-Cadinene & $\mathrm{C}_{15} \mathrm{H}_{24}$ & 27.16 & 0.34 \\
\hline 21. & Caryophyllene oxide & $\mathrm{C}_{15} \mathrm{H}_{24} \mathrm{O}$ & 28.90 & 0.32 \\
\hline
\end{tabular}


Table 2 Physicochemical, Druggability, ADMETox properties of Isopulegol

\begin{tabular}{|c|c|c|}
\hline \multicolumn{2}{|c|}{ Physicochemical Properties of Isopulegol } & Value \\
\hline \multicolumn{2}{|l|}{ Molecular weight } & $154.25 \mathrm{~g} / \mathrm{mol}$ \\
\hline \multicolumn{2}{|l|}{ LogP } & 2.36 \\
\hline \multicolumn{2}{|l|}{$\log D$} & 2.32 \\
\hline \multicolumn{2}{|l|}{$\operatorname{LogSw}$} & -2.59 \\
\hline \multicolumn{2}{|l|}{ Number of stereocenters } & 3 \\
\hline \multicolumn{2}{|l|}{ Stereochemical complexity } & 0.300 \\
\hline \multicolumn{2}{|l|}{ Fsp3 } & 0.800 \\
\hline \multicolumn{2}{|l|}{ Topological polar surface area } & $20.23 \AA^{2}$ \\
\hline \multicolumn{2}{|c|}{ Number of hydrogen bond donors } & 1 \\
\hline \multicolumn{2}{|c|}{ Number of hydrogen bond acceptors } & 1 \\
\hline \multicolumn{2}{|c|}{ Number of smallest set of smallest rings (SSSR) } & 1 \\
\hline \multicolumn{2}{|l|}{ Size of the biggest system ring } & 6 \\
\hline \multicolumn{2}{|l|}{ Number of rotatable bonds } & 1 \\
\hline \multicolumn{2}{|l|}{ Number of rigid bonds } & 7 \\
\hline \multicolumn{2}{|l|}{ Number of charged groups } & 0 \\
\hline \multicolumn{2}{|l|}{ Total charge of the compound } & 0 \\
\hline \multicolumn{2}{|l|}{ Number of carbon atoms } & 10 \\
\hline \multicolumn{2}{|l|}{ Number of heteroatoms } & 1 \\
\hline \multicolumn{2}{|l|}{ Number of heavy atoms } & 11 \\
\hline \multicolumn{2}{|c|}{ Ratio between the number of non-carbon atoms and the number of carbon atoms } & 0.1 \\
\hline \multicolumn{2}{|c|}{ Druggability Properties of Isopulegol } & \\
\hline \multicolumn{2}{|l|}{ Lipinski's rule of 5 violations } & 0 \\
\hline \multicolumn{2}{|l|}{ Veber rule } & Good \\
\hline \multicolumn{2}{|l|}{ Egan rule } & Good \\
\hline \multicolumn{2}{|c|}{ Oral PhysChem score (Traffic Lights) } & 0 \\
\hline \multicolumn{2}{|l|}{ GSK's 4/400 score } & Good \\
\hline \multicolumn{2}{|l|}{ Pfizer's 3/75 score } & Warning \\
\hline Weighted quantitative estimat & (QEDw) score & 0.576 \\
\hline Solubility & & 11585.15 \\
\hline Solubility Forecast Index & & Good \\
\hline ADMET Properties of Isopul & & \\
\hline Property & Value & Probability \\
\hline Human Intestinal Absorption & HIA+ & 0.989 \\
\hline Blood Brain Barrier & $\mathrm{BBB}+$ & 0.887 \\
\hline Caco-2 permeable & Caco2+ & 0.819 \\
\hline P-glycoprotein substrate & Substrate & 0.515 \\
\hline P-glycoprotein inhibitor I & Non-inhibitor & 0.692 \\
\hline P-glycoprotein inhibitor II & Non-inhibitor & 0.972 \\
\hline CYP450 2C9 substrate & Non-substrate & 0.846 \\
\hline
\end{tabular}




\begin{tabular}{|c|c|c|}
\hline CYP450 2D6 substrate & Non-substrate & 0.853 \\
\hline CYP450 3A4 substrate & Substrate & 0.569 \\
\hline CYP450 1A2 inhibitor & Non-inhibitor & 0.808 \\
\hline CYP450 2C9 inhibitor & Non-inhibitor & 0.917 \\
\hline CYP450 2D6 inhibitor & Non-inhibitor & 0.926 \\
\hline CYP450 2C19 inhibitor & Non-inhibitor & 0.856 \\
\hline CYP450 3A4 inhibitor & Non-inhibitor & 0.848 \\
\hline CYP450 inhibitory promiscuity & L-CYP Inhibitory Promiscuity & 0.883 \\
\hline Ames test & Non AMES toxic & 0.956 \\
\hline Carcinogenicity & Non-carcinogens & 0.891 \\
\hline Biodegradation & Ready biodegradable & 0.553 \\
\hline Rat acute toxicity & $1.875 \mathrm{LD}_{50}, \mathrm{~mol} / \mathrm{kg}$ & NA \\
\hline hERG inhibition (predictor I) & Weak inhibitor & 0.655 \\
\hline hERG inhibition (predictor II) & Non-inhibitor & 0.837 \\
\hline \multicolumn{3}{|c|}{ Toxicity Risk of Isopulegol towards Drugability/ Drug Score } \\
\hline Mutagenic property & & None \\
\hline Tumorigenic property & & None \\
\hline Irritant property & & None \\
\hline Effect on reproduction & & None \\
\hline Drug Likeliness & & -21.93 \\
\hline Drugability Score & & 0.46 \\
\hline
\end{tabular}

NOTE: Physicochemical properties: FAF-Drugs4/ RDKit open-source cheminformatics platform. Druggability properties were computed using FAFDrugs4/FAF-QED open source platform. ADMET properties were predicted admetSAR open-source tool 